A qualitative investigation into the HIV disclosure process within an intimate partnership: 'the moment I realized that our relationship was developing into something serious, I just had to tell him'

Charlotte Smith, Department of Psychology, Anglia Ruskin University, Cambridge UK Rachel Cook, Department of Psychology, Anglia Ruskin University, Cambridge UK Poul Rohleder, School of Psychology, The University of East London, London UK

Accepted 24 October 2016 for publication in the British Journal of Health Psychology This article may not exactly replicate the final version published in the journal. 


\title{
A qualitative investigation into the HIV disclosure process within an intimate partnership: 'the moment I realized that our relationship was developing into something serious, I just had to tell him'
}

\begin{abstract}
Objectives. This study sought to elucidate the process through which people living with HIV (PLWH) in the United Kingdom disclose their status to an intimate partner (IP).

Design. A qualitative cross-sectional survey design was used.

Method. A total of 95 PLWH took part. They were presented with a series of open-ended questions enquiring into their last experience of disclosing to an IP. The data was analyzed using thematic analysis.

Results. Disclosure became a salient issue when the discloser acknowledged their relationship as meaningful. A decision to tell was mostly made in order to build a foundation for the evolving relationship. Once the decision was made, it was enacted via one of two mechanisms (self-initiated or opportunistic) and partners' reported reactions fell within one of four main reaction types. In the long-term for couples that remained together, disclosure was understood to have brought them closer. However, for both those whose relationships remained intact, and for those whose relationship had since broken down, sexual difficulties associated with being in a sero-discordant partnership pervaded. At a personal level, the experience resulted in increased confidence in living the diagnosis, and an increased sense of disclosure mastery.

Conclusions: Disclosure is a highly nuanced process. In particular, it was found to be largely characterized by the IP relational context in which it was occurring. The clinical and theoretical implications of these findings are discussed. In particular, these findings highlight a need for the provision of long-term support to PLWH in negotiating their relationships throughout the process.
\end{abstract}




\section{INTRODUCTION}

Human Immunodeficiency Virus (HIV) is a communicable disease, and disclosure of one's HIV status has been an important component of preventing onwards transmission. Since the development of effective medical treatment, HIV disclosure has become all the more important as people living with HIV (PLWH) can now expect to live a normal lifespan; disclosure now represents a fundamental and ongoing part of living with the disease (Feigin, Sapir, Patinkin \& Turner, 2013). HIV disclosure represents a form of psychological adjustment to a HIV+ diagnosis (Rodkjaer, Chesney, Lomborg, Ostergaard, Laursen \& Sodemann, 2014), as well as acting as a gateway for further social (Mburu, Hodgson, Kalibala, Haamujompa, Cataldo, Lowenthal \& Ross, 2014), medical (Elopre, Hook, Westfall, Zinski, Mugavero, Turan \& Van Wagoner, 2015; Ostermann et al, 2015) and emotional support (Yonah, Fredrick \& Leyna, 2014), and improved quality of life (MutabaziMwesigire, Seeley, Martin, \& Katamba, 2014).

The UNAIDS (2015) states that HIV disclosure has been relatively neglected in research and global HIV interventions to date. It is well established that stigma is the major inhibitor of disclosure, and social support increases odds of disclosing (Arnold, Rebchook, \& Kegeles, 2014; Smith, Rossetto \& Peterson, 2008). It has also been established that disclosure varies according to the relationship in which it is occurring; with differing relationship contexts being associated with varying motivations and barriers to disclosing (Dima, Stutterheim, Lyimo \& de Bruin, 2014).

There have been attempts to develop a theoretical model of HIV disclosure which can inform HIV disclosure interventions ultimately aimed at reducing HIV transmission, supporting adjustment for PLWH and informing future research (Chaudoir \& Fisher, 2010; Chaudoir, Fisher \& Simoni, 2011). In early models, HIV disclosure was conceptualized as an instant event that occurs at one point in time, resulting from certain disclosure cognitions triggering a corresponding behavior (disclosure or concealment) (Arnold, Rice, Flannery, \& RotheramBorus, 2008). It is increasingly being recognized however that disclosure occurs through a process (Gachanja \& Burkholder, 2016), taking place over an extended period of time and through a set of distinct stages (Li, Qiao, de Wit, \& Sherr, 2015). However, the exact process through which disclosure occurs remains poorly understood.

A number of studies into HIV disclosure have identified some distinct stages in the process (Amoran. 2012; Rodkjaer, Sodemann, Ostergaard \& Lomborg, 2011; Serovich, Oliver, Smith, \& Mason, 2005). A qualitative study by Gaskins, Payne, Sowell, Gardner, Lewis and Parton (2012) provided an account of the process through which 40 African-American men shared their HIV+ status within a non-specified relationship setting. However, the model developed from these findings did not extend beyond the initial phase in which the individual made a disclosure decision; thus it resulted in only a 'model of making decisions'. Further, the size and homogeneity of the sample limits generalizability of the findings.

A theoretical 'disclosure processes model' (DPM) (Chaudoir et al, 2011) was developed which aimed to provide the first process-based explanatory account of HIV disclosure. The DPM has been well received in the literature; particularly, it breaks away from the traditional reductionist tendency to view disclosure in terms of certain cognitions/ circumstances and resulting behavior (Qiao, Li, \& Stanton, 2013). However, the model has some limitations that are important to consider. Predominantly, the account of the process provided was structured according to pre-defined stages of disclosure identified in the literature (Chaudoir, 2009). 
Further, despite claiming to be an explanatory model, the DPM is not able to explain how people progress from one stage to the next. This is arguably where the importance of a process theory of HIV disclosure lies: this understanding could enable clinicians to assist people in successfully navigating each stage, and enacting a disclosure with a safe and positive outcome (Chaudoir \& Fisher, 2010).

The aim of the study reported on in this paper was to add to this emerging understanding of the HIV disclosure process by attempting to provide a comprehensive account of the process of disclosure to an intimate partner (including both its pathway and mechanisms), through investigating the reported experiences of individuals living with HIV in the United Kingdom (UK).

\section{METHOD}

Qualitative data was collected as part of a mixed-methods survey examining disclosure within an intimate partner context (quantitative data from this survey has been published elsewhere; BLINDED, 2016). This qualitative component of the survey focused on the disclosure process respondents, all PLWH, reportedly engaged in. Respondents were asked to recall their last experience of telling an intimate partner about their HIV status, and to provide responses in reference to this. The term 'intimate partner' was not defined apriori by the researcher.

The survey was developed for the purposes of this study. It was informed by a review of the literature, and discussions with a national HIV organization. Questions were piloted with a group of 4 PLWH ( 2 females and 2 males) and was reviewed by a CEO of a national HIV charity. The survey did not require any major revisions following this pilot.

Respondents were provided with a choice of filling in a paper copy of the survey, or completing it online (using the software Surveygizmo).

Within the survey, respondents were presented with a series of open-ended questions aiming to elicit their recollections of the process they engaged in when disclosing to their partner. These were:

1. What was your thought process that led you to finally decide that you were going to tell your partner?

2. Explain how you told your partner about your HIV

3. How did your partner instantly react upon being told of your HIV?

4. If you are not with this person and in an intimate relationship, why did the relationship end?

5. Explain how your relationship with this person changed after they found out about your HIV/ how it stayed the same

6. Explain how this particular experience of disclosing your status to an intimate partner has changed you

Respondents were provided with text boxes in which to enter responses (with no word limits). Ethical approval was obtained from the ethics panel of the lead author's institution. 


\section{Respondents}

Respondents were recruited via 31 HIV (or HIV-related) organizations in the UK. The survey was advertised via the organizations' social media networks. Paper flyers advertising the survey were also issued to service users on charity premises.

In total, 95 people situated throughout the UK completed the survey, between February and November 2013. Around two thirds of the sample were men which is proportionate to the distribution of HIV in the UK (PHE, 2014). The sample was representative of key groups affected by HIV including self-identified gay, bisexual and other men who have sex with men (herein referred to as MSM), and black African heterosexual men and women (UNAIDS, 2014) (see table 1).

\section{Analysis}

The typical respondent addressed each of the 6 questions in 1-2 paragraphs of text. The data were analyzed using thematic analysis (Braun, Clarke \& Terry, 2015), adopting both a deductive (informed by the questions asked) and inductive approach. General themes from the text were initially identified by the first author (CS) after repeatedly reading the transcripts and becoming immersed in the data set. These themes then went through a process of cross-validation with the second and third author. Where the validity of themes were debated, the team returned to the data- if the theme did not hold up in light of the evidence, it was removed. A strength of thematic analysis is that it enables both convergences and potential divergences to be identified within the sample. This is particularly valuable when considering the contrasting socio-cultural contexts in which two predominant sub-groups of the sample (MSM and black-African heterosexual men and women) were embedded

\section{RESULTS}

The themes and sub-themes are presented below. Each reflect moments during the process of HIV disclosure, including pre-disclosure, the act of disclosure and post-disclosure (see Table 2).

\section{Pre-disclosure Process: Thinking about disclosing as a fundamental part of acknowledging a developing relationship}

\section{Perceived obligation to disclose to the partner}

Many respondents disclosed because of a perceived obligation to do so. Typical responses were:

'I need to be honest about my status' (R 59, black Caribbean MSM male)

'my thought process has always been that I had a responsibility to disclose' (R 38, whiteBritish MSM male)

However, in addition to this sense of obligation, thinking about disclosing also related to a sense of acknowledging the potential development of a deepening relationship, as reflected in the following theme. 


\section{Reflecting on the intimate relationship as being meaningful}

A need to disclose was immediately linked to meeting someone with whom the respondents were beginning to develop a meaningful relationship. It was in the context of this early, developing relationship that the issue of disclosure became salient, with respondents reporting that they 'had' to tell at this point in the relationship.

I wanted to have a significant relationship with them. Once I had recognized and accepted that thought, I then thought well he needs to know' (R 52, white-British MSM male)

'ultimately I knew that if I wanted this to work long term, it needed to come out into the open' (R 89, white-British MSM male)

Within this theme disclosure was seen to take on one of two meanings. For some, disclosure was seen as an opportunity to build a long-term, trusting relationship. For others, disclosure was used as a test, to determine whether it would be 'worth' continuing to emotionally invest in the relationship.

For one group of respondents, disclosure presented an opportunity to practice honesty in the relationship, so as to build trust and a 'firm foundation'; it became a facilitator for creating the positive relationship they desired.

'I knew I had to be honest going into a relationship, and if it was to be built on trust, then obviously I had no option but to disclose' (R 6, white-British MSM male)

'I do not want to be guarded or set up mistrust. And I want a relationship that is tuneful and without fear, warts and all' (R 89, white-British heterosexual male)

The respondents who adopted this perspective were mostly optimistic that their disclosure would contribute to the establishment of a successful and long lasting partnership.

In contrast, other respondents felt much less optimistic about disclosing. This group (mostly white-British MSM) was more mindful of the risks involved in disclosing and the threat that this presented to the relationship. Disclosure then became used as a test to establish the value of future emotional investment.

'things were developing between us very rapidly and so, to avoid wasting either of our time, decided I would tell him at an early stage and before things developed too far between us' ( $\mathrm{R}$ 15, white-British MSM male)

'decided that there was no point in becoming emotionally involved with anyone, and then getting rejected or hurt either directly or indirectly' (R 86, white-British MSM male)

This group approached the decision to disclose from a calculated perspective; it was viewed objectively in terms of not 'wasting' time and emotional investment in the relationship. The decision for this group commonly was to disclose at an early stage, before things developed much further.

\section{Process involved in the act of disclosure}


The findings suggest two mechanisms that explain how the decision to disclose transformed into an action. The first will be referred to as the opportunistic mechanism; for this mechanism, the act of disclosure followed an external, environmental trigger. The second will be referred to as the self-initiating mechanism; here, the disclosure was more anticipated and pre-planned, and instigated by the discloser.

\section{The opportunistic mechanism: 'I thought this was a great opportunity to tell him'}

For one fifth of respondents, the decision to disclose was enacted as a result of an unexpected event that 'pushed' the respondent to tell; the opportunity to disclose arose unexpectedly. For example, some respondents referred to disclosure following an issue arising around the use of condoms:

'the other day I asked if the condom was still on and he said it wasn't and I jumped. So that raised his suspicion and asked why I had jumped. So I told him I was not comfortable without the condom and I didn't know him much meaning I don't know his HIV status. So he went on and showed me his results. So I had to do some drama as I already knew my status. So I lied that I was going to get a test too since he had shown me his. So after a week I asked him to come with me to collect my results from my GP. I knew he was at work and there was no way he was going to come along. So after some time I called him and told him 'honey I told you to come with me and now the GP told me I'm positive', (R 24, black heterosexual female)

Another respondent reported on disclosing following an unexpected diagnosis:

'my partner in the car told me that he had received an odd phone call from the sexual health clinic (that we had attended two weeks earlier). He was struggling to make sense of the purpose of their call as they seemed to have nothing to tell him. I then told him that they had called me too to tell me I was HIV positive, and I had been struggling to keep it together since' (R 3, white-British MSM male)

Interestingly, whilst respondents from all subgroups cited some examples of disclosing through an opportunistic mechanism, this mechanism was used most prominently by those who identified as black-African female. Across all cases, the decision to disclose transformed into an action because in one way or another an unexpected environmental trigger forced the issue to come to a head. The discloser felt in this situation that they had to confront the issue of disclosure, and take an active role.

\section{The self-initiating mechanism: 'I had made a conscious decision not to date/have sex... without telling them I was HIV first'}

The second mechanism, the self-initiating mechanism, was the most common mechanism through which the act of disclosure came about; around half of the respondents' disclosure event was enacted through this mechanism. In contrast to the higher prevalence of the opportunistic mechanism amongst the black-African female subgroup, this self-initiating mechanism was mostly drawn on by the white-British MSM respondents. For this group, the disclosure was initiated by themselves from a pre-planned intention to disclose:

'we went out for dinner with the intention I told him afterwards...I told him I had something very important to tell him to get off my chest' (R 64, white-British MSM male) 
Not only was the decision to disclose a planned one, but the circumstances or setting in which this disclosure was to take place was also planned (a purposive meeting or date).

\section{The partner's reactions to the disclosure}

After disclosing, the reported partner reactions varied considerably within the sample. However, these can be summarized by four main reaction types. These were as follows: the partner reacted well; the partner reacted neutrally; the partner reacted negatively; the partner reacted with shock and silence initially but followed this up with a loving and reassuring reaction.

\section{Reaction type 1: The partner reacted positively}

One third of respondents reported that their partner immediately reacted in a positive manner to the disclosure. In the analysis, three types of positive disclosure reactions emerged. The first was an atmosphere that was emotionally contained, presented through the partner demonstrating a controlled response upon receiving the disclosure. Common reports included the partner remaining 'calm' and composed. The discloser felt a sense of reassurance from this reaction, that they had not overwhelmed the partner, and this in turn made the experience of disclosing more comfortable for them.

'there was no rejection and no castigation, just warmth and understanding, a caring compassionate pastoral engagement with the situation as it was. I was surprised at how quickly she was able to be at ease with the situation. She was not overly concerned by the disclosure. Her reaction was supportive warm and comforting. it took a load of weight off my mind' ( $\mathrm{R}$ 39, white-British heterosexual male)

'his response seemed measured. He remained calm. He informed me that he wasn't about to run out the door' (R 37, black Caribbean heterosexual female)

A second aspect of a positive disclosure reaction was the partner reacting in a supportive manner. This support took on many forms and appeared to vary according to the partnership. Examples include reminding the person to take medication, or providing emotional support. One notably common supportive reaction in the sample emerged, involving a reassuring seeking of physical contact with the discloser.

'he hugged me tighter and said-that's okay. It's not a problem. Come on-let's go upstairs. I apologized for not raising it earlier. He told me not to be daft and hugged me more' (R 85, white-British MSM male)

A third aspect of a positive disclosure reaction included an offering of reassurance by the partner that they did not negatively judge them for having HIV.

'he said it didn't change how he thought about me' (R 52, white-British MSM male)

\section{Reaction type 2: The partner reacted neutrally}

A very small proportion of white-British MSM respondents reported an immediate reaction from their partner that could be classified as neutral. For this subgroup, their partners did not appear to manifest any desirable or blatantly negative responses. In direct contrast to the group 
whose partners reacted positively they did not appear moved at all by the disclosure, rather presenting as indifferent, or 'neutral' as one respondent stated. A typical response to this effect was:

'quite neutral really. Neither angry nor upset' (R 79, white-British MSM male)

\section{Reaction type 3: The partner reacted negatively}

One fifth of the sample (mostly consisting of men and women who identified as black-African), reported that their partner immediately reacted negatively to the disclosure. At the root of many negative reactions from partners was a fear that they too may have contracted HIV within the relationship.

'DISBELIEF ... followed by blaming me of being unfaithful and putting him at risk' (R 59, white-British MSM male)

'started crying saying that now it might happen for that she is also positive' (R 70, black African heterosexual male)

In very few cases this led the partner to subsequently reject the discloser outright. In other instances, the partner threatened that if they were found not to have contracted HIV from the discloser (i.e. were HIV negative after testing), they would abandon the partner.

she told me that if she gets tested and she is found negative our marriage will be over and immediately she phoned her mother in Africa telling her everything and she made her point very strong to her mother that if she get tested and found negative she would leave me' (R 70, black African heterosexual male)

'he looked at me for a few seconds, got up, and walked out of the restaurant. He didn't say one single word. He's never spoken to me since' (R 59, black Caribbean MSM male)

One, more frequently-reported, aspect of a negative reaction was the partner becoming emotionally uncontained. Some partners manifested extreme emotional responses; they cried and felt 'shock'. Their behavior was equally unregulated; for example, the partner dramatically 'fell to the floor'.

she hit the roof and started crying' (R 70, black African heterosexual male)

'heavy breathing, shock, fell to the floor, and was also sick' (R 16, white-British MSM male)

This reaction stands in direct contrast to the calm response manifested by those partners who were interpreted as having reacted positively (see above).

\section{Reaction type 4: The partner immediately reacted with silence/ shock and then expressed love and provided reassurance}

This was the most complex of the disclosure reaction types. For this group, their partners immediately responded with silence and/ or shock but shortly followed this up with a reassuring and loving response. 
'his reaction was shock, disbelief...he went into his workshop, shut the door, lit a fag and cried. When he came round to, he said that wasn't going to stop him and that he still loved me anyway' (R 4, black African heterosexual female)

'he never called me again for 2 weeks...until after 2 weeks he called and apologized for his silence as he was so shocked to know that I was carrying the virus.... he realized that 'my heart still loves you' (R 24, black heterosexual female)

This reflected a 'slow to warm up' reaction. The initial reaction often took the form of disengaging from the disclosure process, followed by a reassuring response.

\section{Post-disclosure processes}

\section{Consequences for the relationship}

For a minority of respondents, disclosure of their HIV status led to negative consequences for their relationships. In most cases, this centered around difficulties in their sex lives:

'we didn't have sex again' (R 85, mixed-white and Asian MSM male)

From the 35 respondents who declared that they had split with their partner since the disclosure event (36.84\%), only 6 cited HIV as contributing to the breakdown of the relationship. Of this, only one person believed that the disclosure alone 'made it end'.

Three out of those 6 respondents cited sexual difficulties related to being in a sero-discordant relationship as the main factor leading to the break down. For example:

'he had a habit of trying to have unsafe sex, whilst still being afraid of HIV. Although I had an undetectable viral load, there wasn't enough known about transmission risk then. It happened a couple of times where I gave in and let him carry on without a condom, but he was so distraught afterwards that it was too difficult to take. We broke up briefly after the first occasion, but got back together. When it happened again I broke it off completely, as I couldn't bear the thought that I might end up being the cause of his contracting HIV' (R 41, whiteBritish MSM male)

A further two respondents reported that their relationships broke down due to the emotional strain that the HIV diagnosis placed on the partnership:

'it did put emotional strain on the relationship. That was more because of me than him though to be honest, I needed breathing space and time to come with my diagnosis. He wasn't very understanding of the processes involved in coming to terms with something which is so life changing, or at least life altering' (R 26, white-British MSM male)

The remaining respondent reported that their partner left them after meeting 'a younger man who was not HIV positive...in short, someone whose future prospects were not blighted by HIV'. 
These findings suggest that it is highly uncommon for the disclosure to result in an instant rejection by the partner. Rather, it appears that in a small number of PLWH who disclose, HIVrelated issues begin to developing, leading to a gradual breakdown of the partnership.

In contrast, around half of the sample reported that the disclosure had had a positive influence on their relationship. Disclosure appeared to increase the level of emotional intimacy shared thereafter. A typical statement was that 'it brought us closer together' (respondent 64, whiteBritish MSM). An examination of the accounts reveals that disclosure is not merely communicating to the other person that they have HIV, but represents something more meaningful in the context of the partnership. It represents an interaction with the partner where they are emotionally opening themselves up and making an emotional investment in the partnership.

'HIV has opened a door to talk about and explore the things that make us both vulnerable and strong, the things that are empowering and the things that can hold us back. It was an opening for getting an understanding about each others thoughts and beliefs...it helped us not to be too guarded' (R 89, white-British heterosexual female)

As well as increasing emotional intimacy in the relationship, disclosure also often resulted in a gesture of increased commitment to the relationship by the partner (e.g. a proposal, or a commitment ring). This worked to reaffirm and solidify the partners' bond.

\section{Onwards and upwards: personal mastery of HIV disclosure, and the HIV diagnosis}

In terms of the long-term consequences of disclosure to the individual, two themes emerged. Firstly, respondents reported that the disclosure had led to a feeling of mastery over their HIV diagnosis (what Holmes \& Shea, (1997) refer to as 'HIV mastery'). Secondly, respondents reported that, in particular, the disclosure experience led to an increased feeling of mastery over HIV disclosure.

\section{HIV mastery}

One in three people who disclosed reported undergoing a positive personal change since their disclosure; they felt a sense of mastery in living with HIV. This long-term consequence of disclosing was reported most frequently by the female black-African subgroup.

For some, HIV mastery came about through a process of 'coming to the realization'- where the meaning that they held about HIV changed. For example, one respondent stated that they now 'treat it like another chronic illness'. Another respondent stated that this sudden realization consisted of their partner helping 'me to see it for what it is, a disease- not a moral judgment'. For another respondent their partner made them realize that 'there are a lot worse things one could be having to deal with than an HIV positive status'.

For other respondents this HIV mastery came about as a result of a change in affect and perspective. These respondents expressed feeling newly 'positive', 'happy' and 'confident' about their HIV status, and 'empowered'. For example:

'the experience made me more in charge of my life and my destiny' ( $\mathrm{R} 1$, white-British heterosexual female) 
'disclosing has made me more confident about how I live and deal with having HIV. I feel quite liberated' (R 85, white-British MSM male)

For another set of respondents, this HIV mastery came about as a result of the discloser becoming more accepting of their diagnosis and of themselves as acceptable. For example, one discloser reflected upon the disclosure event:

'it made me realize people can still love me even with my diagnosis which I thought would never happen' (R 53, white-British MSM male)

\section{Disclosure mastery}

Around one in four respondents reported a greater sense of mastery in relation to disclosing their HIV, as a long-term positive effect of the reported experience. Specifically, they reported a greater sense of ease in approaching disclosure in the future. Male respondents in particular reported this as a consequence of disclosing.

'I am becoming more confident in telling a partner from the start' ( $\mathrm{R} 59$, black Caribbean MSM male)

\section{DISCUSSION}

The results suggest that the process of disclosure within an intimate partnership is closely linked with the subjective experience of a deepening relationship, and part of an emotional investment in the relationship. The process of disclosure for the PLWH involves considerable engagement with experiencing the relationship as increasingly meaningful, rather than just being a purely instrumental health-related activity (i.e. fulfilling an obligation to disclose or as part of the process of negotiating safe sex; Serovich \& Mosack, 2003). While some of this obligation to disclose might be understood in terms of the criminalization of non-disclosure, the respondents described a sense of obligation in terms of being a moral and honest partner. Similarly, Flowers and Davis (2012) highlight disclosure as a "socially loaded" (pg 720) experience, intricately linked to identity and relationships; not just a health behavior associated with the medical normalization of HIV. A meaningful and long-term relationship has been previously associated with increased odds of disclosing (Amoran, 2012; Loukid et al, 2014).

While for some, disclosure arose opportunistically as similarly observed by Gaskins and colleagues 2012, for others it was a planned activity. Regardless of how the act of disclosure took place, it was clear from the results that disclosure seemed to act as a defining act for the relationship. For some, it was used as a test to establish the value of future emotional investment; for others it was seen as an opportunity to set a foundation for the relationship they desired to follow. The former is in line with speculations made by Greene, Derlega, Yep and Petronio (2003) that one benefit of disclosing early on in a developing relationship is that if 'rejection occurs...there is (hopefully) a relatively small investment in the relationship...many of those [PLWH] might not want to 'waste time' skirting around the issue' (p. 53). Secondly, finding that disclosure presents itself to others as an opportunity to build a relationship that the PLWH desires reiterates a recent conclusion drawn by Xiao, Lu, Qiao, Zhou, Shen and Tang (2015).

An interesting finding is that HIV disclosure mostly resulted in a positive or supportive reaction from the partner, and longer-term positive consequences for the relationship. This is in contrast 
to findings that non-disclosure occurs most frequently out of fear of distressing others or facing stigma and discrimination (Petrak, Doyle, Smith, Skinner \& Hedge, 2001). However, it is important to note that the respondents who reported a negative partner reaction were mostly black-African men and women.

In most cases, this fear may not turn out to be justified, certainly within an intimate partnership. It appears that for those respondents who were no longer in the relationship, this did not appear to be as a result of an immediate stigmatizing reaction by the partner towards their HIV+ status. Rather, the findings suggest that a subsequent break down represented later HIV-related stresses that arose more gradually in the partnership, including the sexual issues related to being in a sero-discordant partnership (see Palmers \& Bor, 2001), and the emotional burden that HIV places on the couple. This account of the relationship deterioration following a disclosure lends itself favorably to a clinical intervention. Interventions that assist sero-discordant couples in having a safe and satisfying sexual relationship and in coping with the emotional implications of HIV in the relationship, may prove effective in terms of maintaining the relationship in the longer term. This is in keeping with other studies that highlight the reported need of men living with HIV to find ways of living satisfying sexual lives (for example Bourne, Hickson, Keogh, Reid \& Weatherburn, 2012; BLINDED, in press). Considering that most disclosure interventions focus only on assisting PLWH to perform a disclosure (Conserve, Groves \& Maman, 2015), these findings suggest that a shift to a longitudinal supportive approach is necessary in HIV disclosure interventions.

There is further scope for these findings to enhance current supportive practices provided by HIV organizations around the UK. Firstly, at present a strategic and practical approach to supporting PLWH in navigating disclosure is mostly adopted (e.g. individuals are encouraged to decide on a place to disclose that will ensure their safety, and the reasons for and against making a decision to disclose are considered; Serovich, Reed, Graftsky, \& Andrist, 2009). These new findings suggest that incorporating an experiential element into current supportive practices may further enhance their efficacy, through attending to the rich (and at times, challenging) experiential dimension of the disclosure process. Secondly, whilst some HIV organizations provide a supportive package on disclosure that looks at disclosure generally across all relationship settings, the present findings suggest that disclosure to an intimate partner is a highly nuanced process, and so a disclosure intervention should be tailored to this specific relationship context at least.

The results suggest that the process of disclosure also had personal benefits for the individual. Following the disclosure, respondents' feelings of mastery grew- both in relation to their HIV+ diagnosis, and HIV disclosure. The latter finding is congruent with the 'disclosure feedback loop' of the DPM (Chaudoir et al., 2011). This mastery may further explain the recent links reported between disclosure and quality of life (Mutabazi-Mwesigire et al, 2014), and increased adjustment to the diagnosis (Rodkjaer et al, 2014). This could also be understood from the notion of post-traumatic growth, where there may be a positive change, such as a reappraisal of one's life and relationships, following working through the trauma associated with a threatening illness (Hefferon, Grealy \& Mutrie, 2009).

It is worth noting that whilst this study aimed to provide an overview of the core convergences and divergences in the process of disclosing to an intimate partner in the overall sample, some interesting contrasts in the process emerged in the process of analyzing the data. It was found that the MSM (majority white British) respondents cited using disclosure as a test to establish the value of future emotional investment more frequently as a driver to disclose, and also 
disclosed through the self-initiated mechanism much more frequently, in comparison to their black-African heterosexual counterparts- who predominantly disclosed opportunistically. The black-African subgroup also tended to report a negative reaction more frequently. These contrasting disclosure tendencies indicate that the subjective experience of disclosing potentially also varies as a function of the ethnicity, gender and sexual orientation of the sample. These differences, and why, are areas for further investigation, but what our data does suggest is that given that black-African respondents were more likely to report disclosing in an opportunistic manner, and receiving negative reactions from their partners in response, it may be that waiting for an opportunity to disclose may mean waiting for a potentially "safe opportunity. In the UK context, where HIV has always been most prevalent among MSM, it may be that disclosure has become more normalized among MSM (although the stigma has not).

These findings are relevant for the wider literature on disclosure of a range of health conditions to an intimate partner. They emphasize the entwined relationship between disclosure and intimacy. In the current sample, disclosure became salient once a level of intimacy had been achieved in the partnership (Greene et al, 2003), and many perceived disclosure as a way of further increasing the intimacy of the relationship. This is most relevant when it comes to disclosure of hidden health conditions. This entwined association between disclosure and intimacy encapsulates the early theoretical literature on self-disclosure (Chelune, Vosk, Waring, Sultan \& Ogden, 1984); decades later, self-disclosure generally is still held as fundamental to forming bonds and deepening relationships (Erber \& Erber, 2016). However, despite movements towards the 'normalization' of HIV (Squire, 2013), there remain additional complexities in disclosing HIV, given the pervasive stigma that continues to exist. Thus, despite the era of effective treatment, HIV continues to have far reaching implications for the discloser's identity, with disclosure being a form of stigmatized identity management (Murphy, Hevey, O’Dea, Rathaille \& Mulcahy, 2015).

There are limitations to this study that need to be acknowledged. One potential limitation is that the study explored the disclosure experience as retrospectively recalled by respondents and thus may be inaccurately recalled. However, whilst this issue has been acknowledged in HIV disclosure research (most of which uses retrospective designs), it has also been stated that due to the highly personal experience of disclosing 'the salience of the [HIV disclosure] events is likely to be high and thus the reporting fairly accurate' (Gielen, McDonnell, Burke \& O'Campo, 2000, p. 118) thereby reducing the risk of inaccurate recall (Denis, 2014). In addition, the study also relied on respondents recruited through HIV community organisations, who might have already benefitted from the support, and thus feel more empowered. It is also important to note that whilst it was considered a strength of the study that the intimate partnership was not defined by the length of time in the relationship, it is possible that respondents may have reported on disclosure experiences with more casual, short-term partners. However, the findings remain important regardless of this.

In conclusion, this study provides a nuanced account of the disclosure process within an intimate partnership. The importance of the discloser's subjective experience in the unfolding process was demonstrated. The findings point to a fundamental need for the availability of long-term support for individuals in negotiating their relationships throughout the disclosure process, particularly in negotiating the sexual and emotional domains, moving forwards from the disclosure event. Furthermore, disclosure has tended to be viewed from a medical perspective, as a means of accessing support and care to aid treatment and prevent onwards 
transmission. With HIV now being a chronic condition, we need to think a lot more about supporting relationships.

\section{REFERENCES}

Amoran, O.E. (2012). Predictors of sero-status to sexual partners among people living with HIV/AIDS in Ogun State, Nigeria. Nigerian Journal of Clinical Practice, 15(4), 38590. doi: 10.4103/1119-3077.104507.

Arnold, E.A., Rebchook, G.M., \& Kegeles, S.M. (2014). 'Triply cursed': racism, homophobia and HIV-related stigma are barriers to regular HIV testing, treatment adherence and disclosure among young black gay men. Culture, Health \& Sexuality, 16(6), 710-22. doi: 10.1080/13691058.2014.905706

Arnold, M.E., Rice, E., Flannery, D., \& Rotheram-Borus, M.J. (2008). HIV disclosure among adults living with HIV. AIDS Care, 20(1), 80-92. doi: 10.1080/09540120701449138

Bourne, A., Hickson, F., Keogh, P., Reid, D., \& Weatherburn, P. (2012). Problems with sex among gay and bisexual men with diagnosed HIV in the United Kingdom. BMC Public Health, 12, 916. doi: 10.1186/1471-2458-12-916.

Braun, V., Clarke, V., \& Terry, G. (2015). Thematic analysis. In P. Rohleder and A.C. Lyons (Eds.), Qualitative research in clinical and health psychology (pp. 95-113). Basingstoke: Palgrave Macmillan.

Chaudoir, S.R. (2009). HIV/ AIDS decision-making and outcomes: a longitudinal, eventbased analysis. (Unpublished doctoral dissertation). University of Connecticut, America.

Chaudoir, S. R., \& Fisher, J. D. (2010). The disclosure processes model: understanding disclosure decision making and postdisclosure outcomes among people living with a concealable stigmatized identity. Psychological Bulletin, 72(10), 1618-29. doi: $10.1037 / \mathrm{a} 0018193$

Chaudoir, S. R., Fisher, J. D., \& Simoni, J. M. (2011). Understanding HIV disclosure: a review and application of the disclosure processes model. Social Science \& Medicine, 72(10), 1618-29. doi: 10.1016/j.socscimed.2011.03.028

Chelune, G.J., Vosk, B.N., Waring, E.M., Sultan, F.E., \& Ogden, J.K. (1984). Self-disclosure and its relationship to marital intimacy. Journal of Clinical Psychology, 40(1), 216-9.

Conserve, D.F., Groves, A.K., \& Maman, S. (2015). Effectiveness of interventions promoting HIV serostatus disclosure to sexual partners: a systematic review. AIDS \& Behavior, 19(10), 1763-72. doi: 10.1007/s10461-015-1006-1.

Denis, P. (2014). New patterns of disclosure: how HIV-positive support group members from kwazulu-natal speak of their status in oral narratives. Medical History, 58(2), 278297. doi: $10.1017 / \mathrm{mdh} .2014 .23$

Dima, A. L., Stutterheim, S. E., Lyimo, R., \& de Bruin, M. (2014). Advancing methodology in the study of HIV status disclosure: The importance of considering disclosure target and intent. Social Science \& Medicine, 108, 166-174. doi: 10.1016/j.socscimed.2014.02.045

Elopre, L., Hook, E.W., Westfall, A.O., Zinski, A., Mugavero, M.J., Turan, J., \& Van Wagoner, N. (2015). The role of early HIV status disclosure in retention in HIV care. AIDS Patient Care \& STDS, 29(12), 646-50. doi: 10.1089/apc.2015.0205. 
Erber, R., \& Erber, M.W. (2016). Self-presentation and self-disclosure. In R. Eber \& M.W. Erber ( $2^{\text {nd }}$ ed.), Intimate Relationships: Issues, Theories and Research (pp. 73-90). London: Routledge.

Eustace, R. W., \& Ilagan, P. R. (2010). HIV disclosure among HIV positive individuals: a concept analysis. Journal of Advanced Nursing, 66(9), 2094-2103. doi: 10.1111/j.1365-2648.2010.05354.x

Feigin, R., Sapir, Y., Patinkin, N., \& Turner, D. (2013). Breaking through the silence: the experience of living with HIV-positive serostatus, and its implications on disclosure. Social Work \& Health Care, 52(9), 826-445. doi: 10.1080/00981389.2013.827143

Flowers, P. \& Davis, M.D.M. (2012). Understanding the biopsychosocial aspects of HIV disclosure among HIV-positive gay men in Scotland. Journal of Health Psychology, 18(5), 711-724.

Gachanja, G., \& Burkholder, G.J. (2016). A model for HIV disclosure of a parent's and/or a child's illness. Peer Journal, 4(4), 1662. doi: 10.7717/peerj.1662

Gaskins, S.W., Payne, P.F., Sowell, R.L., Gardner, A., Lewis, T.L., \& Parton, J.M. (2012). Making decisions: the process of HIV disclosure for rural African American men. American Journal of Men's Health, 6(6), 442-52. doi: 10.1177/1557988312439405.

Gielen, A. C., McDonnell, K. A., Burke, J. G., \& O'Campo, P. (2000). Women's lives after an HIV-positive diagnosis: disclosure and violence. Maternal and Child Health Journal, 4(2), 111-120.

Greene, K., Derlega, V. J., Yep, G. A., \& Petronio, S. (2003). Privacy and disclosure of HIV in interpersonal relationships: A sourcebook for researchers and practitioners. London: Routledge.

Hefferon, K., Grealy, M., \& Mutrie, N. (2009). Post-traumatic growth and life threatening physical illness: A systematic review of the qualitative literature. British Journal of Health Psychology, 14, 343-378. doi: 10.1348/135910708X332936

Holmes, W. C., \& Shea, J. A. (1997). Performance of a new, HIV/AIDS-targeted quality of life (HAT-QoL) instrument in asymptomatic seropositive individuals. Quality of Life Research, 6(6), 561-571. doi: 10.1023/A:1018464200708

Li, X., Qiao, S., de Wit, J., \& Sherr, L. (2015). What's in the telling? Understanding social, psychological and clinical aspects of HIV disclosure. AIDS Care, 27(Sup1), 1-5. doi: 10.1080/09540121.2015.1102687

Loukid, M., Abadie, A., Henry, E., Hilali, M.K., Fugon, L., Rafif, N.,...Preau, M. (2014). Factors associated with HIV status disclosure to one's steady sexual partner in PLWHIV in Morocco. Journal of Community Health, 39, 50-59. doi: 10.1007/s10900-013-9739-0

Mburu, G., Hodgson, I., Kalibala, S., Haamujompa, C., Cataldo, F., Lowenthal, E.D., \& Ross, D. (2014). Adolescent HIV disclosure in zambia: barriers, facilitators and outcomes. Journal of International AIDS Society, 10(17), 18866. doi: 10.7448/IAS.17.1.18866.

Murphy, P.J., Hevey, D., O’Dea, S., Rathaille, N.N., \& Mulcahy, F. (2015). Serostatus disclosure, stigma resistance, and identity management among HIV-positive gay men in Ireland. Qualitative Health Research, 26(11), 1459-72. doi: 10.1177/1049732315606687.

Mutabazi-Mwesigire, D., Seeley, J., Martin, F., \& Katamba, A. (2014). Perceptions of quality of life among Ugandan patients living with HIV: a qualitative study. BMC Public Health, 14, 343-353. doi: 10.1186/1471-2458-14-343

Ostermann, J., Pence, B., Whetten, K., Yao, J., Itemba, D., Maro, V.,...Thielman, N. (2015). HIV serostatus disclosure in the treatment cascade: evidence from Northern Tanzania. AIDS Care, 27(Sup1), 59-64. doi: 10.1080/09540121.2015.1090534 
Palmers, R., \& Bor, R. (2001). The challenges to intimacy and sexual relationships for gay men in HIV serodiscordant relationships: a pilot study. Journal of Marital Family Therapy, 27(4), 419-31. doi: 10.1111/j.1752-0606.2001.tb00337.x

Petrak, J.A., Doyle, A., Smith, A., Skinner, C., \& Hedge, B. (2001). Factors associated with self-disclosure of HIV serostatus to significant others. British Journal of Health Psychology, 6, 69-79. doi: 10.1348/135910701169061

Public Health England. (2014). HIV in the United Kingdom: 2014 report. London: Author.

Qiao, S., Li, X., \& Stanton, B. (2013). Theoretical models of parental HIV disclosure: A critical review. AIDS Care, 25(3), 326-336. doi: 10.1080/09540121.2012.712658

Rodkjaer, L., Chesney, M.A., Lomborg, K., Ostergaard, L., Laursen, T., \& Sodemann, M. (2014). HIV-infected individuals with high coping self-efficacy are less likely to report depressive symptoms: a cross-sectional study from Denmark. International Journal of Infectious Diseases, 22, 67-72. doi: 10.1016/j.ijid.2013.12.008.

Rodkjaer, L., Sodemann, M., Ostergaard, L., \& Lomborg, K. (2011). Disclosure decisions: HIV positive persons coping with disease-related stressors. Qualitative Health Research, 21(9), 1249-59. doi: 10.1177/1049732311405803

Serovich, J.M., \& Mosack, K.E. (2003). Reasons for HIV disclosure or nondisclosure to casual sexual partners. AIDS Education \& Prevention, 15(1), 70-80.

Serovich, J.M., Oliver, D.G., Smith, S.A., \& Mason, T.L. (2005). Methods of HIV disclosure by men who have sex with men to casual sexual partners. AIDS Patient Care and STDs, 19(12), 823-32. doi: 10.1089/apc.2005.19.823

Serovich, J.M., Reed., S., Graftsky, EL., \& Andrist, D. An intervention to assist men who have sex with men disclose their serostatus to casual sex partners: results from a pilot study. AIDS Education and Prevention, 21(3), 207-219. doi: 10.1521/aeap.2009.21.3.207.

Smith, R., Rossetto, K., \& Peterson, B. L. (2008). A meta-analysis of disclosure of one's HIV-positive status, stigma and social support. AIDS Care, 20(10), 1266-1275. doi: 10.1080/09540120801926977

Squire, C. (2013). Living with HIV and ARVs. Three Letter Lives.: London: Palgrave.

UNAIDS. (2015). How AIDS Changed Everything. Switzerland: Author.

UNAIDS. (2014). The Gap Report. Switzerland: Author.

Xiao, Z., Li, X., Qiao, S., Zhou, Y., Shen, Z., \& Tang, Z. (2015). Using communication privacy management theory to examine HIV disclosure to sexual partners/spouses among PLHIV in Guangxi. AIDS Care, 27(Sup1), 73-82. doi: 10.1080/09540121.2015.1055229.

Yonah, G., Fredrick, F., \& Leyna, G. (2014). HIV serostatus disclosure among people living with HIV/AIDS in Mwanza, Tanzania. AIDS Research and Therapy, 22(11), doi: 10.1186/1742-6405-11-5

BLINDED. (in press). Experience of sexual self-esteem among men living with HIV. Journal of Health Psychology

BLINDED. (in press). Taking into account the quality of the relationship in HIV disclosure. AIDS \& Behavior 


\begin{tabular}{|c|c|c|}
\hline \multicolumn{3}{|c|}{ Table 1: Sample Demographics $(\mathrm{N}=95)$} \\
\hline & $\mathrm{n}$ & $(\%)$ \\
\hline \multicolumn{3}{|l|}{ Gender } \\
\hline Male & 70 & (73.68) \\
\hline Female & 25 & $(26.32)$ \\
\hline \multicolumn{3}{|l|}{ Age range } \\
\hline 18-24 years & 2 & $(0.02)$ \\
\hline 25-34 years & 21 & (22.11) \\
\hline $35-49$ years & 41 & $(43.16)$ \\
\hline $50+$ years & 31 & (32.63) \\
\hline \multicolumn{3}{|l|}{ Sexual orientation } \\
\hline Gay male & 59 & $(62.1)$ \\
\hline Heterosexual male & 11 & $(11.58)$ \\
\hline Lesbian female & 2 & $(0.02)$ \\
\hline Heterosexual female & 22 & $(23.16)$ \\
\hline Bisexual female & 1 & $(1.05)$ \\
\hline \multicolumn{3}{|l|}{ Education } \\
\hline Secondary school & 15 & (15.79) \\
\hline College/ sixth form & 27 & $(28.42)$ \\
\hline University & 53 & $(55.79)$ \\
\hline \multicolumn{3}{|l|}{ Ethnicity } \\
\hline White British & 69 & (72.63) \\
\hline White Irish & 3 & $(3.16)$ \\
\hline White other & 5 & $(5.26)$ \\
\hline Mixed white and black Caribbean & 1 & $(1.05)$ \\
\hline Mixed white and Asian & 1 & $(1.05)$ \\
\hline Mixed white and other & 1 & $(1.05)$ \\
\hline Black Caribbean & 4 & $(4.21)$ \\
\hline British African & 9 & $(9.47)$ \\
\hline Black other & 1 & $(1.05)$ \\
\hline Other & 1 & $(1.05)$ \\
\hline \multicolumn{3}{|l|}{ Region in the UK } \\
\hline England & 80 & $(84.21)$ \\
\hline Wales & 4 & $(4.21)$ \\
\hline Scotland & 10 & $(10.53)$ \\
\hline Channel Islands and Isle of Man & 1 & $(1.05)$ \\
\hline \multicolumn{3}{|l|}{ Relationship status } \\
\hline Single & 25 & $(26.32)$ \\
\hline Dating & 17 & $(17.90)$ \\
\hline Cohabiting & 24 & $(25.26)$ \\
\hline Married & 11 & (11.58) \\
\hline Civil partnership & 9 & $(9.47)$ \\
\hline Separated & 3 & $(3.16)$ \\
\hline Divorced & 4 & $(4.21)$ \\
\hline Widowed & 2 & $(0.02)$ \\
\hline \multicolumn{3}{|l|}{ Length of time since diagnosis* } \\
\hline$\leq 5$ years & 25 & $(27.47)$ \\
\hline $6-10$ years & 12 & $(13.19)$ \\
\hline $11-15$ years & 15 & $(16.48)$ \\
\hline $16-20$ years & 17 & (18.68) \\
\hline $21-25$ years & 10 & $(10.99)$ \\
\hline$\geq 26$ years & 12 & $(13.19)$ \\
\hline \multicolumn{3}{|l|}{ Medium of disclosure* } \\
\hline Face to face & 44 & $(66.66)$ \\
\hline Online & 9 & $(13.64)$ \\
\hline Mobile text/ telephone & 13 & $(19.7)$ \\
\hline$* \mathrm{~N}=91$ and $\mathrm{N}=66$ respectively due $\mathrm{t}$ & & \\
\hline
\end{tabular}




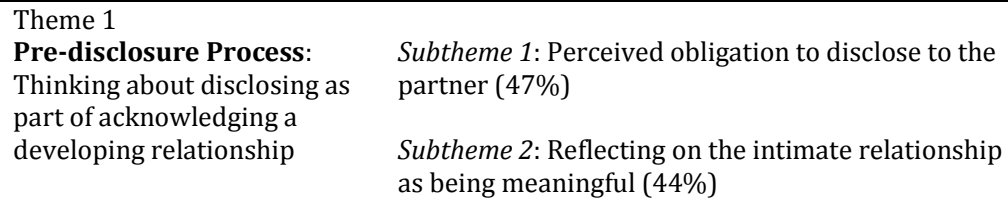

Subtheme 2: Reflecting on the intimate relationship as being meaningful (44\%)

\begin{tabular}{|c|c|}
\hline $\begin{array}{l}\text { Theme } 2 \\
\text { Processes involved in the } \\
\text { act of disclosing }\end{array}$ & $\begin{array}{l}\text { Subtheme 1: The opportunistic mechanism: 'I } \\
\text { thought this was a great opportunity to tell him' } \\
(22 \%)\end{array}$ \\
\hline & $\begin{array}{l}\text { Subtheme } 2 \text { : The self-initiating mechanism: 'I had } \\
\text { made a conscious decision not to date/have } \\
\text { sex...without telling them I was HIV first' (49\%) }\end{array}$ \\
\hline $\begin{array}{l}\text { Theme } 3 \\
\text { The partner's reactions to } \\
\text { the disclosure }\end{array}$ & $\begin{array}{l}\text { Subtheme 1: Reaction type 1: The partner reacted } \\
\text { positively (33\%) } \\
\text { Subtheme 2: The partner reacted neutrally (4\%) } \\
\text { Subtheme 3: The partner reacted negatively }(20 \%) \\
\text { Subtheme 4: The partner immediately reacted with } \\
\text { silence/ shock and then expressed love and } \\
\text { provided reassurance }(21 \%)\end{array}$ \\
\hline $\begin{array}{l}\text { Theme } 4 \\
\text { Post-disclosure processes }\end{array}$ & $\begin{array}{l}\text { Subtheme 1: Consequences for the relationship } \\
\text { Subtheme 2: Onwards and upwards: personal } \\
\text { mastery of HIV disclosure, and the HIV diagnosis }\end{array}$ \\
\hline
\end{tabular}

Table 2. A table of the overarching theme and subthemes that emerged during the analysis of the process. 